\title{
A forced-choice preferential looking task for the assessment of vision in dogs: pilot study
}

Kathleen L. Grahama BVSc(Hons1) MVS MANZCVS

Sarah-Elizabeth Byosiere ${ }^{b}$

Lynna C. Fengb

Matthew Sanders ${ }^{c}$ BVSc(Hons) MANZCVS

Pauleen C. Bennettb

Kelly Caruso BSc VMD DACVOd

Christina McCowan ${ }^{\mathrm{e}, \mathrm{f}}$ BVSc BSc (Hons) PhD MANZCVS DACVP

Andrew White ${ }^{\mathrm{a}, \mathrm{g}}$ BMedSci(Hons) MBBS PhD FRANZCO

aClinical Ophthalmology and Eye Health, Sydney Medical School, University of Sydney, NSW Australia

bSchool of Psychology and Public Health, La Trobe University, Victoria, Australia

${ }^{c}$ Animal Eye Care, Malvern East, Victoria Australia

dEye Clinic for Animals, Crows Nest, NSW Australia

eUniversity of Melbourne Veterinary Hospital, University of Melbourne; Victoria Australia

fDepartment of Economic Development, Jobs, Transport and Resources, Victoria Australia

gWestmead Institute for Medical Research, Westmead, NSW Australia

Keywords: canine, dog, functional vision, preferential looking task, vision, visual acuity

\section{Corresponding author:}

Kathleen L. Grahama BVSc(Hons1) MVS MANZCVS

kathleen.graham@sydney.edu.au, klgraham007@gmail.com

\begin{abstract}
Objective: To describe preliminary use of a forced-choice preferential looking task for the clinical assessment of vision in dogs
\end{abstract}

This is the author manuscript accepted for publication and has undergone full peer review but has not been through the copyediting, typesetting, pagination and proofreading process, which may lead to differences between this version and the Version of Record. Please cite this article as doi: 10.1111/jsap.12965

This article is protected by copyright. All rights reserved. 
Materials and Methods: The vision of 18 pet dogs was investigated in two separate studies using a forced-choice preferential looking task: multiple observers watched eye, head and body movements on video recordings to identify cues suggesting when a dog had seen the feature of interest. Human observer reliability was determined using eight dogs and computer-generated stimuli. Visual acuity was assessed using computer-generated grating stimuli: in real-time, an observer watched each dog's eye movement patterns and behaviour to decide whether each grating was or was not seen. Stimuli were presented in a step-wise manner and were controlled by the observer. Acuity was estimated as the highest spatial frequency the dog was determined to have seen.

Results: Median estimated visual acuity was better at 1 metre compared to 3 metres. Average test time was longer at a 3-metre distance than at 1 metre. Inter- and intra-observer reliability was better from 1 metre than from 3 meters.

Conclusion and clinical relevance: Preliminary use of a forced-choice preferential looking task for measurement of visual acuity in dogs has potential use as a clinical tool for the assessment of vision in dogs.

Keywords: Canine, dog , functional vision , preferential looking task , vision , visual acuity

This article is protected by copyright. All rights reserved. 


\section{Introduction}

Accurate assessment of vision in veterinary patients is difficult. Our incomplete understanding of the components of canine vision, as well as the inability of nonverbal species to provide feedback, means that tools used to assess vision in humans are not directly transferable to dogs. Instead, assessment of canine visual performance in a veterinary clinical setting is limited to methods such as testing for a menace response, visual placing, tracking objects and navigating obstacle courses (Ollivier, Plummer \& Barrie 2007). These methods do not readily allow for objective assessments or quantification of visual function.

Visual acuity (VA) refers to the ability to distinguish details of an object with clarity (Walls 1963) and remains unsurpassed as a clinical tool for vision assessment in people (Westheimer 2016). VA is determined by an interaction of optical and neural factors based on an animal's anatomy and physiology (Odom, Bromberg \& Dawson 1983). While VA is not a complete measure of visual function, a correlation with quality of life and visual function has been demonstrated, and VA has been used as a primary indicator of functional vision impairment in people (Brenner et al. 1993; Carta et al. 1998; Fletcher et al. 1997; Gutierrez et al. 1997; Mangione et al. 1996; Steinberg et al. 1994).

Preferential looking (PL) tasks have been developed to assess the VA of infants and preverbal children and are based on their preferential fixation on a boldly

This article is protected by copyright. All rights reserved. 
patterned target when it is paired with a blank target of equal luminance (Fantz 1958). In PL tasks the assessor is masked to the location and spatial frequency of the grating and uses the child's eye and/or head movement to judge the location of the stimulus (Gwiazda et al. 1978; Teller 1979). PL and operant procedures have been used to assess VA of normal infants and children (Atkinson, Braddick \& Pimm-Smith 1982; Boothe, Dobson \& Teller 1985; Dobson \& Teller 1978) as well as in those with known or suspected visual disorders (Jacobson, Mohindra \& Held 1982; Mayer, D \& Dobson 1980), and have been shown to be reliable and easy to administer in these individuals (McDonald et al. 1985; Teller et al. 1986).

Due to a lack of objective measures of vision in animals, PL tasks may be a suitable means of obtaining measurable indicators of vision in these species. The aim of this study was to determine the suitability of a forced-choice PL (FPL) task for use in the clinical assessment of vision in dogs with no previous training or acclimatisation to the testing procedure.

\section{Materials and methods}

Two separate studies were performed to address each of the main variables in a FPL task. Human observer reliability was initially assessed to determine whether the perception that the dog saw the stimulus was consistent between observers. Assessment of canine visual acuity was subsequently tested.

For inclusion in either study an ophthalmic examination was required for all dogs. Examination included slit-lamp biomicroscopy, indirect ophthalmoscopy, tonometry (Icare TonoVet, Icare, Finland), measurement of tear production 
(Schirmer Tear Test; Merck Animal Health, NJ, USA), and paddle retinoscopy (Sussex Vision International, West Sussex UK). All procedures and protocols were conducted in accordance with the Association for Research in Vision and Ophthalmology statement on the Use of Animals in Ophthalmic and Vision Research and with approval from the University of Sydney Animal Ethics Committee.

\section{Observer (human) reliability assessment}

Animals: The study was conducted on eight privately-owned Lagotti Romagnoli dogs that had been target-trained to touch a stimulus (the larger circle displayed) on a screen for separate studies (Byosiere, S-E et al. 2017; Byosiere et al. 2016; Byosiere, S et al. 2017).

Stimulus: Stimuli were presented on two second-generation Apple iPads (screen size 9.7 inch; screen resolution $1024 \times 768$ pixels) mounted adjacent to each other on their long side. Display settings on both devices were set to maximum brightness (device internal settings) throughout the testing procedures.

A specialised optotype (i.e. a letterform used in an eyechart) consisted of the letter ' $O$ ' in black, displayed on a white background as used in a standard Snellen visual acuity chart (constructed on a $5 \times 5$ grid so that the size of the critical detail subtended one-fifth of the overall height). Each optotype was composed of lines to subtend a visual angle from the testing distance, conforming to the principles of standard logarithmic visual acuity charts. Acuity was reported on a 'logarithm of the minimum angle of resolution' (logMAR) scale, which is a linear scale

This article is protected by copyright. All rights reserved. 
providing a measure of vision loss (lower logMAR values indicate better visual acuity). Optotypes were presented in order of decreasing size to test visual acuities ranging from logMAR 1.6 to logMAR 0.3 (eight trials: 1-metre testing distance) and logMAR 11.48 to logMAR -0.12 (11 trials: 3-metre testing distance) (Fig.1).

Experimental procedure: Testing was conducted in the same enclosed room with the same personnel present for all trials. The owner was present but not involved in the testing procedure. Each dog participated in four sessions (two trials at 3metre testing distance, followed by two at 1-metre testing distance) on the same day.

An investigator, blinded to the stimulus display location, gently held the dog's head at a pre-marked distance ( 1 or 3 metres from the screens). Investigators $A$ and $B$ held a shield $(94 \times 55 \mathrm{~cm})$ to obstruct the dog's view of the stimuli between each trial. When the dog looked toward the shield (as identified by investigators $A$ and B), it was lifted so the stimuli were visible to the dog. The handling investigator (investigator $\mathrm{C}$ ) held the dog stationary for 1 second before releasing the dog's collar and allowing the dog to approach and touch the screen displaying the optotype. The dog received a food reward (Good-o treats ${ }^{\circledR}$ ) from a remotecontrolled food dispensing device (Treat \& Train Remote Reward Dog Trainer $^{\circledR}$, PetSafe, Dubai, UAE) for correct identification of the target and for returning to the start point for the next trial.

For each trial, two investigators ( $A$ and $B$ ) were obliged to decide whether the dog 'chose' its target before leaving the testing mark. If the dog did not touch the 
screen displaying the optotype, or if the dog's 'choice' was determined to have been made after leaving the testing mark, the previous (larger) optotype was presented in the next trial. The experimental session ended if three consecutive errors were made when presented with the same optotype, with correct identification of the previous (larger) optotype between each of these errors.

Each session was recorded using two digital video cameras (Sony HDR-CX405 Memory Stick HD Camcorder), one positioned directly above the screens, facing the dog and the other positioned behind the dog to record the dog and both screens throughout each trial.

Analysis: Three investigators independently reviewed video footage of each trial at a later date. Each investigator was required to make a choice on five separate criteria based on their observation of that video clip (Table 1). All trials (517) were assessed by one investigator on two separate occasions, 2 weeks apart, to determine intra-rater reliability. Percentage agreement and a one-way intraclass correlation coefficient (ICC) was used to determine inter- and intra-rater reliability at both testing distances.

\section{Canine vision (estimated visual acuity) assessment}

Case selection: Ten privately-owned dogs with no history of ophthalmic disease or vision impairment, and no previous training to interact or respond to a computer-generated stimulus were included. Dogs were excluded if there was any refractive error detected on streak retinoscopy.

This article is protected by copyright. All rights reserved. 
Stimulus: Stimuli were generated using PsychoPy coding software(Peirce 2009) on an Apple MacBook Pro (Intel HD Graphics 40001536 MB; Apple MacBook Pro 2011) and presented on a 21.5 -inch screen (1920 X 1080 pixels) resulting in 72 and 212 pixels per degree, and a horizontal field of view of $27^{\circ}$ and $9^{\circ}$ when viewed from 1 and 3 metres respectively. Testing was conducted in a room with overhead lights on and average luminance on the stimulus of 30 candelas $/ \mathrm{m}^{2}$. A stimulus panel consisted of one patterned stimulus and one homogenous grey stimulus. The patterned stimulus was a static square sinusoidal grating that varied in spatial frequency ( 0.28 to 15 cycles/degree) with average screen luminance of 85 candelas $/ \mathrm{m}^{2}$ and Michelson contrast of $90 \%$ (Fig.2). Luminance of the grey stimulus matched the mean luminance of the patterned stimulus, and was close to that of the background screen to minimise contrast at the edge of the stimuli. Two additional 'anchor' stimuli, a blank and a $10 \mathrm{cycle} /$ degree grating, were available for use as necessary to provide anchor points for the investigator's judgment during testing.

Experimental procedure: A rapid-assessment FPL task based on that used in the assessment of visual acuity in human infants (McDonald et al. 1985) was designed for this study. Grating acuity was tested with a two-alternative forcedchoice paradigm in which the grating was oriented vertically in a random order and displayed in a random position on the screen. Dogs were given breaks as deemed necessary by the investigator. Each dog had two sessions at two separate clinic visits. Each testing session consisted of assessment from both 1and 3-metre distances. All sessions were conducted in the same room with the 
same equipment and by the same investigator to ensure consistency between conditions.

The dog was held at the appropriate viewing distance for that session. The investigator (observer) was shielded from view by a screen behind the display monitor to minimise distractions in the dog's visual field. This observer had a laptop which controlled display of stimuli. Testing was conducted in a manner similar to that reported for the rapid test of infant acuity (McDonald et al. 1985). Briefly, stimuli of low frequency as well as blank anchor cards were initially displayed, allowing the investigator to become familiar with the 'looking style' of each dog in the presence and absence of a visible stimulus. Stimuli were then presented in a random order. The investigator could also choose to display anchor cards as a known stimulus, or a separate animation with accompanying sound to catch the dog's attention (Fig.2b).

For each grating, the investigator pressed a key according to their choice: left arrow indicating 'yes' (the dog had seen the grating) or right arrow indicating 'no' (if the dog appeared not to see the grating). If the investigator could not make a choice, the up-arrow key presented a stimulus of the same spatial frequency (Fig.2c-d). Gratings of the same spatial frequency were displayed until the left or right arrow key were pressed. The estimated VA was the highest spatial frequency with a 'yes' decision in that subset.

Data Analysis

This article is protected by copyright. All rights reserved. 
For analyses of estimated visual acuity, notations were converted to the logMAR equivalent to enable calculation of the geometric mean and standard deviation as previously described (Holladay 1997). A Wilcoxon matched-pairs signed rank test was identify differences in estimated acuity between testing distances.

Spearman's correlation was used to measure the strength and direction of the association between estimated acuity at 1- and 3-metre testing distances.

Estimates of VA were converted into commonly used units.

\section{Results}

Baseline demographics, ophthalmic findings and refractive errors are presented in Table 2. There were no structural ophthalmic abnormalities, history or clinical signs of ocular disease, nor any evidence of vision impairment in any dog. One dog used in proof of concept trials $(G)$ was being treated for diabetes mellitus diagnosed 15 months before testing, but had no evidence of cataract formation and physical examination was unremarkable.

\section{Observer (human) reliability outcomes}

A total of 517 trials ( 243 trials at 1 metre; 274 trials at 3 metres) were completed. One dog (M) did not approach the stimuli in sequential trials during the third session and was withdrawn from the study at that point. The remaining seven dogs completed all four sessions.

This article is protected by copyright. All rights reserved. 
Intra-observer reliability for all trials was $82.4 \%(426 / 517)$; the values for each distance were $94.2 \%$ (ICC $0.91 ; 95 \%$ CI: $0.85,0.94)$ at 1 metre $(229 / 243)$, and $79.8 \%($ ICC $0.72 ; 95 \% \mathrm{CI}: 0.67,0.76)$ at 3 metres $(197 / 247)(p<0.001)$. Interobserver reliability was better at 1 metre $(81.3 \%$, ICC $0.84 ; 95 \%$ CI: $0.75,0.83)$ than 3 metres $(60.2 \%$, ICC $0.64 ; 95 \%$ CI: $0.58,0.66)(p<0.001)$. Agreement between observer decision and correct stimulus location was highest when the cue was the direction the dog looked before moving $(67 \%)$, and when the cue was any one or more behaviours/movements of the dog $(67 \%)$.

\section{Estimated visual acuity outcomes}

All dogs completed all trials conducted and a total of 40 estimates of VA were made from each viewing distance. Average test time was longer from a 3-metre testing distance (6.2 minutes) compared to 1 -metre (4.8 minutes) $(p=0.032)$.

The highest estimated VA for each dog from each testing distance, and expressed in frequently used units, is presented in Table 3 . The median estimated VA was better from 1 metre (logMAR 0.6; range 0.3-1.1; 95\% CI: 0.663-0.76) compared to 3 metres (logMAR 0.8; range $0.6-1.3 ; 95 \%$ CI: $0.78-0.88)(p<0.001)$ (Fig.3). There was a moderate, positive monotonic correlation between estimated VA from 1 and 3 metres $\left(n=40, r_{s}=0.510 ; p<0.001\right)$ (Fig.4). Poorer estimates of acuity were obtained with greater frequency from a 3 metres than from 1 metre.

\section{Discussion}

This article is protected by copyright. All rights reserved. 
In this study, preliminary use of a FPL task was used to obtain measures of visual function (estimated VA) in dogs with clinically normal eyes. Development of a test that provides an objective and quantifiable measure of vision would provide a useful tool in both veterinary ophthalmology and neurology to aid in diagnosis and management of diseases such as glaucoma and retinopathies that result in vision loss, and in assessment of central nervous system lesions affecting the visual pathway. Because formal two-alternative FPL testing may require a large number of trials (Teller 1983), such procedures are not practical for use in pet dogs, especially in a clinical setting. Instead, the study presented here was modeled on a rapid FPL test for use in infants (McDonald et al. 1985), where limitations in time and co-operation are also encountered. FPL procedures are used clinically and allow accurate subjective estimates of binocular and monocular VA in human infants (Atkinson, Braddick \& Pimm-Smith 1982; McDonald et al. 1985; Teller et al. 1986). This pilot study suggests clinical use of a FPL task may be of similar use in dogs.

The use of optokinetic nystagmus (Bloom \& Berkley 1977; Cameron et al. 2013; Ezeh et al. 1990; Schmid \& Wildsoet 1998) and other preliminary tools (Graham et al. 2018; Miller \& Parisi 2018) to measure vision have been described, yet, there is no 'gold standard' measure of visual acuity or visual function in dogs. Establishing validity of our test as a measure of VA is therefore difficult. The initial trials assessing human observer reliability were performed to identify specific criteria (behaviours or cues) that might be used by the investigators to reliably make a choice about whether the dog saw the stimulus. In this study, no specific cue (head turn, eye movement, body movement) achieved greater

This article is protected by copyright. All rights reserved. 
agreement between observer perception and stimulus location than when one specific cue was used. No defined behaviour or cue was therefore used to determine whether the dog had seen the stimulus in the subsequent pilot study. This lack of definition increases subjectivity in this FPL task, and this limitation is also encountered with human infants (Atkinson, Braddick \& Pimm-Smith 1982; McDonald et al. 1985; Teller et al. 1986). With a range of behaviours that may indicate that the subject has seen the stimulus, limiting identification to one or more specific cues may decrease sensitivity of the tool. To minimise the impact of this variable in this pilot study, personnel experienced in working with animals (rather than personnel experienced in conducting similar assessments in humans) were used to assess inter- and intra-observer reliability, and a single observer used in assessments of estimated visual acuity. Caution must be used in drawing conclusions as this subjectivity means validation of the FPL task as a clinical tool requires a large sample population with multiple assessors. It is for this reason, that the results using those dogs previously trained to interact with a screendisplay, and approach the stimulus, were discarded in the analysis of VA estimates. In clinical veterinary medicine, it is more appropriate that this limitation be considered rather than avoided, and thus the term 'estimated visual acuity' has been used in this study with the acknowledgement of different measures of acuity obtained with behavioural and electrophysiologic testing paradigms in domestic animal species (Clark \& Clark 2013).

Inter- and intra-rater reliability were assessed using percent agreement in this study. Justification for using this method included the small sample size, previous 
training of the dogs and experience of each observer, as well as the use of predetermined 'rules' by which observations should be made. Percent agreement does not account for choices when the observer may have guessed the location of the stimulus. Therefore, there is a possibility that inter- and intra-reliability may overestimate the true agreement among observers in this study. Further assessment of this task as a clinical tool requires appropriate sample sizes that allow valid statistical analyses including the assessment of disagreement, 'no agreement', and consistency within and between observers.

The nature of a FPL task presents two variables that might influence results: the visual capability and performance of the dog and the investigator's perception of whether the presented stimulus was seen by the dog. Despite the limitations of both dog and observer variables in a FPL task, estimated VAs were comparable to those previously reported using alternative methods (Ezeh et al. 1990; Murphy et al. 1997; Odom, Bromberg \& Dawson 1983; Tanaka et al. 2000). To limit the number of variables in this pilot study, only emmetropic dogs were included. In addition, results from those dogs with previous training responding to a computer-generated stimulus that were allowed to approach the stimulus (as opposed to remaining at the testing distance) were excluded from analysis in calculating estimated VA. Ongoing validation of the technique to include dogs with measured refractive errors is indicated as these are reported in association with size (Gaiddon, Bouhana \& Lallement 1996) breed (Black et al. 2008; Kubai et al. 2008; Mutti, Zadnik \& Murphy 1999; Williams et al. 2011) age (Kubai et al. 2008; Murphy, Zadnik \& Mannis 1992; Ofri 2013) and skull shape (Gaiddon, Bouhana \& Lallement 1996; Ofri 2013). With validation of the technique, some 
determination of the impact of factors such as hypermetropia, myopia and astigmatism on functional vision, might be made.

Although this testing method was developed based on techniques used in nonverbal people, caution must be used in using VA obtained using these procedures to compare visual capabilities between these species. According to the World Health Organization criteria for defining visual ability (Virgili et al. 2006), most dogs in this study would be classified as having poor vision. Whilst the apparent lack of any visual impairment in all dogs assessed may be attributed to the paucity of appropriate measures of vision in domestic animal species, it is essential to consider the other components of vision, and that the relative importance of these factors varies considerably between species. For this reason, a clinical tool such as this FPL task must be utilised as what it is - a means of obtaining a measurable indicator of one of the components of vision. Other available tests as well as clinical and ophthalmic examinations must be performed in conjunction with any tool such as a FPL task in order to obtain the most wellrounded assessment possible.

Traditional testing of VA involves the use of high contrast optotypes or gratings even though VA is understood to transcend optical resolution.(Westheimer 2016) The importance of discrimination mechanisms other than resolution (e.g. contrast reduction, noise and contour perturbation) on canine vision remains unknown and was not explored in this study. Measures of various components of vision,

This article is protected by copyright. All rights reserved. 
including functional vision using obstacle courses,(Annear et al. 2013; Garcia et al. 2010) visual acuity using target detection,(Tanaka et al. 2000) colour perception,(Neitz, Geist \& Jacobs 1989) brightness discrimination,(Pretterer et al. 2004) and techniques to assess specific areas of the visual pathway(Ekesten et al. 2013; Willis et al. 2001) have been reported in dogs. These techniques require specialised equipment, facilities, anaesthesia and/or prior training, making them unsuitable for widespread clinical use in veterinary patients. In this pilot study, testing of untrained dogs in a veterinary clinic using equipment already available in the clinic (with purpose-developed software) was timely (4.8 - 6.2 minutes per testing interval) and well tolerated by dogs. Validation of the technique, and assessment of responsiveness (the ability to detect change) in a large population with multiple testers (observers) as would be expected in a clinical setting, is therefore warranted.

Differences between testing paradigms make direct comparisons between studies of VA difficult. By converting reported acuities into a common unit of measure, comparisons between studies may be made, though these conversions should be interpreted with caution as different paradigms measure different types of acuity. Studies in humans have shown fairly good agreement between optotype and grating acuity estimates in normal populations (Dobson et al. 1995; Mayer, DL \& Dobson 1982), and discrepant findings with disease (Kushner, Lucchese \& Morton 1995; Mash \& Dobson 1998). This shows a need for a single paradigm that can be implemented on a large scale to allow direct comparisons within and between dogs.

This article is protected by copyright. All rights reserved. 
This study describes preliminary use of a forced-choice preferential looking task with potential clinical use in the veterinary setting. To justify intervention and treatment of vision impairing ophthalmic diseases in domestic animals and to determine its efficacy, veterinarians and vision researchers need to incorporate objective and/or quantifiable measures of visual function into clinical practice and vision research. The intended use of this test is for the clinical assessment of vision in dogs in conjunction with other tests and clinical examination. This must be considered when interpreting results which are not designed to provide definitive measures of canine visual acuity. We suggest that these results warrant further investigation to assess the validity, reliability and responsiveness of the technique by different observers using a suitably sized study population, including dogs with and without vision-impairing disease.

No conflict of interest has been declared

This article is protected by copyright. All rights reserved. 


\section{References}

Annear, MJ, Gornik, KR, Venturi, FL, Hauptman, JG, Bartoe, JT \& Petersen-Jones, SM 2013, 'Reproducibility of an objective four-choice canine vision testing technique that assesses vision at differing light intensities', Veterinary Ophthalmology, vol. 16, no. 5, pp. 324-8.

Atkinson, J, Braddick, O \& Pimm-Smith, E 1982, "Preferential looking'for monocular and binocular acuity testing of infants', BRITISH JOURNAL OF OPHTHALMOLOGY, vol. 66, no. 4, pp. 264-8.

Black, J, Browning, SR, Collins, AV \& Phillips, JR 2008, 'A canine model of inherited myopia: familial aggregation of refractive error in labrador retrievers', INVESTIGATIVE OPHTHALMOLOGY \& VISUAL SCIENCE, vol. 49, no. 11, pp. 47849.

Bloom, M \& Berkley, M 1977, 'Visual acuity and the near point of accommodation in cats', Vision research, vol. 17, no. 6, pp. 723-30.

Boothe, RG, Dobson, V \& Teller, DY 1985, 'Postnatal development of vision in human and nonhuman primates', Annual review of neuroscience, vol. 8, no. 1 , pp. 495-545.

Brenner, MH, Curbow, B, Javitt, JC, Legro, MW \& Sommer, A 1993, 'Vision change and quality of life in the elderly: response to cataract surgery and treatment of other chronic ocular conditions', Archives of Ophthalmology, vol. 111 , no. 5, pp. 680-5.

Byosiere, S-E, Feng, LC, Chouinard, PA, Howell, TJ \& Bennett, PC 2017, 'Relational concept learning in domestic dogs: Performance on a two-choice size discrimination task generalises to novel stimuli', Behavioural processes, vol. 145, pp. 93-101.

Byosiere, S-E, Feng, LC, Woodhead, JK, Rutter, NJ, Chouinard, PA, Howell, TJ \& Bennett, PC 2016, 'Visual perception in domestic dogs: susceptibility to the Ebbinghaus-Titchener and Delboeuf illusions', Animal Cognition, pp. 1-14.

Byosiere, S, Feng, L, Rutter, N, Woodhead, J, Chouinard, P, Howell, T \& Bennett, P 2017, 'Do dogs see the Ponzo illusion', Animal Behavior and Cognition, vol. 44, no. 4 , pp. 396-412.

Cameron, DJ, Rassamdana, F, Tam, P, Dang, K, Yanez, C, Ghaemmaghami, S \& Dehkordi, MI 2013, 'The optokinetic response as a quantitative measure of visual acuity in zebrafish', Journal of Visualized Experiments, no. 80.

Carta, A, Braccio, L, Belpoliti, M, Soliani, L, Sartore, F, Gandolfi, SA \& Maraini, G 1998, 'Self-assessment of the quality of vision: association of questionnaire score with objective clinical tests', Current eye research, vol. 17, no. 5, pp. 506-12. 
Clark, DL \& Clark, RA 2013, 'The effects of time, luminance, and high contrast targets: Revisiting grating acuity in the domestic cat', Experimental eye research, vol. 116 , pp. $75-8$.

Dobson, V, Quinn, GE, Tung, B, Palmer, EA \& Reynolds, JD 1995, 'Comparison of recognition and grating acuities in very-low-birth-weight children with and without retinal residua of retinopathy of prematurity. Cryotherapy for Retinopathy of Prematurity Cooperative Group', INVESTIGATIVE OPHTHALMOLOGY \& VISUAL SCIENCE, vol. 36, no. 3, pp. 692-702.

Dobson, V \& Teller, DY 1978, 'Visual acuity in human infants: a review and comparison of behavioral and electrophysiological studies', Vision research, vol. 18 , no. 11 , pp. $1469-83$.

Ekesten, B, Komáromy, AM, Ofri, R, Petersen-Jones, SM \& Narfström, K 2013, 'Guidelines for clinical electroretinography in the dog: 2012 update', Documenta Ophthalmologica, vol. 127, no. 2, pp. 79-87.

Ezeh, P, Myers, L, Cummins, K \& Whitley, R 1990, 'Utilizing an optokinetic device in assessing the functional visual acuity of the dog', Progress in Veterinary Neurology, vol. 1, no. 4, pp. 427-32.

Fantz, RL 1958, 'Pattern vision in young infants', The Psychological Record, vol. 8, pp. 43-7.

Fletcher, AE, Ellwein, LB, Selvaraj, S, Vijaykumar, V, Rahmathullah, R \& Thulasiraj, R 1997, 'Measurements of vision function and quality of life in patients with cataracts in southern India: report of instrument development', Archives of Ophthalmology, vol. 115, no. 6, pp. 767-74.

Gaiddon, J, Bouhana, N \& Lallement, P 1996, 'Refraction by retinoscopy of normal, aphakic, and pseudophakic canine eyes: advantage of a 41-diopter intraocular lens?', Veterinary and comparative ophthalmology, vol. 6, pp. 121-4.

Garcia, MM, Ying, G-s, Cocores, CA, Tanaka, JC \& Komáromy, AM 2010, 'Evaluation of a behavioral method for objective vision testing and identification of achromatopsia in dogs', American journal of veterinary research, vol. 71, no. 1 , pp. 97-102.

Graham, KL, Reid, J, Whittaker, CJG, Hall, EJS, Caruso, K, McCowan, CI \& White, A 2018, 'Development of a vision impairment score for the assessment of functional vision in dogs: initial evidence of validity, reliability and responsiveness', Journal of the American Veterinary Medical Association, no. Under review.

Gutierrez, P, Wilson, MR, Johnson, C, Gordon, M, Cioffi, GA, Ritch, R, Sherwood, M, Meng, K \& Mangione, CM 1997, 'Influence of glaucomatous visual field loss on health-related quality of life', Archives of Ophthalmology, vol. 115, no. 6, pp. 777-84. 
Gwiazda, J, Brill, S, Mohindra, I \& Held, R 1978, 'Infant visual acuity and its meridional variation', Vision research, vol. 18, no. 11, pp. 1557-64.

Holladay, JT 1997, 'Proper method for calculating average visual acuity', Journal of Refractive Surgery, vol. 13, no. 4, pp. 388-91.

Jacobson, SG, Mohindra, I \& Held, R 1982, 'Visual acuity of infants with ocular diseases', American journal of ophthalmology, vol. 93, no. 2, pp. 198-209.

Kubai, MA, Bentley, E, Miller, PE, Mutti, DO \& Murphy, C] 2008, 'Refractive states of eyes and association between ametropia and breed in dogs', American journal of veterinary research, vol. 69, no. 7, pp. 946-51.

Kushner, BJ, Lucchese, NJ \& Morton, GV 1995, 'Grating visual acuity with Teller cards compared with Snellen visual acuity in literate patients', Archives of Ophthalmology, vol. 113, no. 4, pp. 485-93.

Mangione, C, Lee, P, Berry, S, Spritzer, K, Janz, N, Klein, R, Owsley, C \& Hays, R 1996, 'The NEI-VFQ 51-item test version and its relationship with visual acuity across 5 diseases', INVESTIGATIVE OPHTHALMOLOGY \& VISUAL SCIENCE, vol. 37, no. 3, pp. 873-.

Mash, C \& Dobson, V 1998, 'Long-term reliability and predictive validity of the Teller Acuity Card procedure', Vision research, vol. 38, no. 4, pp. 619-26.

Mayer, D \& Dobson, V 1980, 'Assessment of vision in young children: a new operant approach yields estimates of acuity', INVESTIGATIVE OPHTHALMOLOGY \& VISUAL SCIENCE, vol. 19, no. 5, pp. 566-70.

Mayer, DL \& Dobson, V 1982, 'Visual acuity development in infants and young children, as assessed by operant preferential looking', Vision research, vol. 22, no. 9, pp. 1141-51.

McDonald, M, Dobson, V, Sebris, S, Baitch, L, Varner, D \& Teller, D 1985, 'The acuity card procedure: a rapid test of infant acuity', INVESTIGATIVE OPHTHALMOLOGY \& VISUAL SCIENCE, vol. 26, no. 8, pp. 1158-62.

Miller, WW \& Parisi, D 2018, 'Development and validation of the canine visual function instrument', Veterinary Ophthalmology, pp. 1-9.

Murphy, CJ, Mutti, DO, Zadnik, K \& Ver Hoeve, J 1997, 'Effect of optical defocus on visual acuity in dogs', American journal of veterinary research, vol. 58, no. 4, pp. 414-8.

Murphy, CJ, Zadnik, K \& Mannis, M 1992, 'Myopia and refractive error in dogs', INVESTIGATIVE OPHTHALMOLOGY \& VISUAL SCIENCE, vol. 33, no. 8, pp. 245963. 
Mutti, DO, Zadnik, K \& Murphy, CJ 1999, 'Naturally occurring vitreous chamberbased myopia in the Labrador retriever', INVESTIGATIVE OPHTHALMOLOGY \& VISUAL SCIENCE, vol. 40, no. 7, pp. 1577-84.

Neitz, J, Geist, T \& Jacobs, GH 1989, 'Color vision in the dog', Visual neuroscience, vol. 3, no. 02, pp. 119-25.

Odom, J, Bromberg, N \& Dawson, W 1983, 'Canine visual acuity: retinal and cortical field potentials evoked by pattern stimulation', American Journal of Physiology-Regulatory, Integrative and Comparative Physiology, vol. 245, no. 5, pp. R637-R41.

Ofri, R 2013, 'Optics and Physiology of Vision', in K Gelatt, BC Gilger \& TJ Kern (eds), Veterinary Ophthalmology, 5th edn, John Wiley \& Sons Inc, Iowa, vol. I, pp. 208-69.

Ollivier, FJ, Plummer, CE \& Barrie, KP 2007, 'Ophthalmic Examination and Diagnostics, Part 1: The Eye Examination and Diagnostic Procedures', in K Gelatt (ed.), Veterinary Ophthalmology, 4th edn, Blackwell Publishing, Iowa, pp. 43876.

Peirce, JW 2009, 'Generating stimuli for neuroscience using PsychoPy', Frontiers in neuroinformatics, vol. 2, p. 10.

Pretterer, G, Bubna-Littitz, H, Windischbauer, G, Gabler, C \& Griebel, U 2004, 'Brightness discrimination in the dog', Journal of vision, vol. 4, no. 3, pp. 10-.

Schmid, KL \& Wildsoet, CF 1998, 'Assessment of visual acuity and contrast sensitivity in the chick using an optokinetic nystagmus paradigm', Vision research, vol. 38, no. 17, pp. 2629-34.

Steinberg, EP, Tielsch, JM, Schein, OD, Javitt, JC, Sharkey, P, Cassard, SD, Legro, MW, Diener-West, M, Bass, EB \& Damiano, AM 1994, 'The VF-14: an index of functional impairment in patients with cataract', Archives of Ophthalmology, vol. 112 , no. 5 , pp. $630-8$.

Tanaka, T, Ikeuchi, E, Mitani, S, Eguchi, Y \& Uetake, K 2000, 'Studies on the visual acuity of dogs using shape discrimination learning', Animal Science Journal, vol. 71 , no. 6, pp. 614-20.

Teller, DY 1979, 'The forced-choice preferential looking procedure: A psychophysical technique for use with human infants', Infant Behavior and Development, vol. 2, pp. 135-53.

- - 1983, 'Measurement of visual acuity in human and monkey infants: the interface between laboratory and clinic', Behavioural brain research, vol. 10, no. 1 , pp. 15-23. 
Teller, DY, McDonald, MA, Preston, K, Sebris, SL \& Dobson, V 1986, 'Assessment of visual acuity in infants and children; the acuity card procedure', Developmental Medicine \& Child Neurology, vol. 28, no. 6, pp. 779-89.

Virgili, G, Acosta, R, Bentley, SA, Giacomelli, G, Allcock, C \& Evans, JR 2006, 'Reading aids for adults with low vision', Cochrane Database Syst. Rev, vol. 18, no. 4 .

Walls, GL 1963, The vertebrate eye and its adaptive radiation, Hafner Pub. Co., New York.

Westheimer, G 2016, 'Optotype recognition under degradation: comparison of size, contrast, blur, noise and contour-perturbation effects', Clinical and Experimental Optometry, vol. 99, pp. 66-72.

Williams, LA, Kubai, MA, Murphy, CJ \& Mutti, DO 2011, 'Ocular components in three breeds of dogs with high prevalence of myopia', Optometry and Vision Science, vol. 88, no. 2, pp. 269-74.

Willis, CK, Quinn, RP, McDonell, WM, Gati, J, Parent, J \& Nicolle, D 2001, 'Functional MRI as a tool to assess vision in dogs: the optimal anesthetic', Veterinary Ophthalmology, vol. 4, no. 4, pp. 243-53. 
Figure 1. Relative differences in the size of optotypes and their corresponding visual acuity values, as used in the assessment of human observer reliability.

Figure 2. a) Schematic diagram representing stimulus panel used to assess visual acuity. The position of the grating stimulus (top left of screen) and homogenous grey stimulus (bottom right of screen) were randomly generated by software. Contrast and luminance are not measured in these representative diagrams; b) Sample animated diagram displayed on screen (with accompanying sound) to re-focus dog's attention at the discretion of the investigator (iStock.com/bandian1122); c-d) Altered positions of stimuli on panel displaying gratings of the same spatial frequency. This sequence was selected by the investigator (up arrow key) when the investigator could not make a 'choice' on where/whether the dog looked at the stimulus, and could be repeated until the investigator made a choice.

Figure 3. Box and whisker plot showing median (range) of estimated visual acuity in dogs. Mean VA represented by cross $(+)$.

Figure 4. Correlation between estimates of visual acuity as measured from 1metre ( $x$-axis) and 3-metres ( $y$-axis)

Table 1. Criteria for investigator decision making in proof of concept trials (determining inter- and intra-rater reliability in a forced-choice looking task)

Table 2. Characteristics and baseline data of subjects 
Table 3. Highest estimated visual acuity recorded for each dog expressed in commonly reported notations

\section{Online supplementary files}

Figure A. Schematic of frontal view displaying stimulus (as presented to dog) showing display monitor in front of a screen concealing the investigator. The investigator views the dog through a small opening in the screen (black rectangle).

Figure B. Schematic representation of testing room in which vision assessments were conducting demonstrating layout of apparatus and personnel (investigator in chair behind desk using laptop which controls the stimulus presentation; handler/owner restraining dog on stool at $1 \mathrm{~m}$ or $3 \mathrm{~m}$ testing distance)

This article is protected by copyright. All rights reserved. 


\section{University Library}

\section{- M M N E R VA A gateway to Melbourne's research publications}

Minerva Access is the Institutional Repository of The University of Melbourne

\section{Author/s:}

Graham, KL;Byosiere, S-E;Feng, LC;Sanders, M;Bennett, PC;Caruso, K;McCowan, Cl;White, A

Title:

A forced-choice preferential looking task for the assessment of vision in dogs: pilot study

Date:

2019-06-01

\section{Citation:}

Graham, K. L., Byosiere, S. -E., Feng, L. C., Sanders, M., Bennett, P. C., Caruso, K., McCowan, C. I. \& White, A. (2019). A forced-choice preferential looking task for the assessment of vision in dogs: pilot study. JOURNAL OF SMALL ANIMAL PRACTICE, 60 (6), pp.340-347. https://doi.org/10.1111/jsap.12965.

Persistent Link:

http://hdl.handle.net/11343/284826 